\title{
Spiritual Intelligence in Relation to Character Strengths and Coping Strategies among Adolescents
}

\author{
Meena Sehga $^{1 *}$, Mitika Kanwar ${ }^{2}$
}

\section{ABSTRACT}

In the present study, Spiritual Intelligence and its correlates were examined among adolescents in order to gain insight into the profile of spiritually intelligent adolescents. Since spirituality can be a protective factor at the tender age of adolescence, a need was felt to envisage the present study. For this purpose, 75 young adults were administered Spiritual Intelligence Self report Inventory (King, 2008), Coping Strategies Inventory (Tobin et al.,1989) and Brief Strengths Test (Peterson \& Seligman, 2004). Intercorrelation analysis of all the variables and multiple regression analysis of character strengths on spiritual intelligence yielded some significant positive results. Engagement coping strategy shared a significant positive association with Spiritual Intelligence $(\mathrm{p}<.01)$. Among character strengths, Spirituality, Gratitude, Self control, Love, Bravery $(\mathrm{p}<.01)$, Appreciation of beauty, Optimism, Leadership, Forgiveness, Social intelligence, Kindness, Love of learning, Curiosity, and Critical thinking $(\mathrm{p}<.05)$ emerged as significant contributors of Spiritual Intelligence. Only Humor shared a negative association with S.I. Therefore, the findings of this study can be used to foster programmes on spiritual intelligence and its development by incorporating exercises for strength building and engagement coping mechanisms.

Keywords: Adolescence, Spiritual Intelligence, Strengths, Coping

Adolescence is marked by the need to seek identity, to know what one is going to take from life, what one is going to give to others and what are one's interests and ideals. In this period there might be identity crisis for those who fail to find an identity for themselves (Erikson, 1968). Spiritual intelligence can act as one of the protective factors for coping with life's major transitions and responsibilities for adolescents (Benavides, 2010). In the present paper, the following research questions were proposed:

\footnotetext{
${ }^{1}$ Professor, Department of Psychology, Panjab University, Chandigarh, India

${ }^{2}$ UGC- Senior Research Scholar, Department of Psychology, Panjab University, Chandigarh, India *Responding Author

(C) 2016 M Sehga, M Kanwar; licensee IJIP. This is an Open Access Research distributed under the terms of the Creative Commons Attribution License (http://creativecommons.org/licenses/by/2.0), which permits unrestricted use, distribution, and reproduction in any Medium, provided the original work is properly cited.
} 


\section{Spiritual Intelligence in Relation to Character Strengths and Coping Strategies among Adolescents}

- Which character strengths are more highly associated with spiritual intelligence among adolescence? and

- $\quad$ Which coping strategies are associated with spiritual intelligence?

\section{Definitions of Spiritual Intelligence}

Spiritual intelligence is defined as a set of mental capacities which contribute to the awareness, integration, and adaptive application of the nonmaterial and transcendent aspects of one's existence, leading to such outcomes as deep existential reflection, enhancement of meaning, recognition of a transcendent self, and mastery of spiritual states (King, 2008). King and Decicco (2009) developed a model of spiritual intelligence which comprised of the following four components: a) Critical Existential Thinking- involves the capacity to critically contemplate meaning, purpose, and other metaphysical issues, such as, death, universe, space, time. Examining the existential purpose of life is also a trait of spirituality but what makes it different in spiritual intelligence is the aspect of critical thinking. Intelligence is reflected in critically thinking, analysing, experiencing, observing, reflecting and communicating's) Personal Meaning Production- is the ability to construct personal meaning and purpose in all the physical and mental experiences. It can be reflected in deriving purpose from daily activities, finding more creative forms of meaning production, and finding meaning from life experiences; c) Transcendental Awareness- involves perceiving the "transcendent dimensions of the self during normal, waking state of consciousness" (King, 2008). TA is also marked by the ability to transcend one's personal limitations and feel connected to something larger than the self, d) Conscious State expansion- is the ability to enter higher states of consciousness. This state of consciousness is pure consciousness, unitive consciousness and cosmic consciousness (Maslow, 1964, Bucke, 1969).It can be achieved through prayer, chanting or meditation by some. Spiritual intelligence is the expression of innate spiritual qualities through your thoughts, actions and attitude (Shivani, 2011).

\section{Difference between being Spiritual and Spiritual Intelligence}

In order to understand spiritual intelligence, it is essential to distinguish it from spirituality for further conceptual clarity. Having Intelligence is to use what you know in the right way at the right time in the right place with the right intention. For example, if one 'knows' him self as a spiritual being he will also 'know' that he does not own or possess anything. When something in life is damaged or lost, it does not affect one in any way - he/she is able to use spiritual power to accept and move on. In effect - one is able to draw on the inner spiritual strength.

\begin{tabular}{|l|l|}
\hline Spirituality & Spiritual Intelligence \\
\hline Spirituality is to know who you are & $\begin{array}{l}\text { Spiritual Intelligence is to realise who you are } \\
\text { and to live in that awareness }\end{array}$ \\
\hline $\begin{array}{l}\text { Spirituality is the knowledge of oneself as a } \\
\text { spirit and understanding highest spiritual }\end{array}$ & $\begin{array}{l}\text { Spiritual Intelligence is the expression of these } \\
\text { innate spiritual qualities through one's }\end{array}$ \\
\hline
\end{tabular}

(c) The International Journal of Indian Psychology, ISSN 2348-5396 (e)| ISSN: 2349-3429 (p) | 215 
Spiritual Intelligence in Relation to Character Strengths and Coping Strategies among Adolescents

\begin{tabular}{|l|l|}
\hline Spirituality & Spiritual Intelligence \\
\hline $\begin{array}{l}\text { qualities such as unconditional love, peace, } \\
\text { purity and bliss }\end{array}$ & thoughts, attitudes and behaviours \\
\hline Being spiritual means the ego has dissolved & $\begin{array}{l}\text { Spiritual intelligence is using this spiritual } \\
\text { knowledge for the upliftment of others }\end{array}$ \\
\hline
\end{tabular}

(Shivani, 2011)

\section{Spiritual intelligence in adolescence}

Due to the emergence of abstract reasoning, spiritual capacities expand in this stage of life. Individuals in the age range of 17-30 years develop meaning making abilities and become more aware of their purpose of existence (Parks, 2000). Spiritual intelligence increases with age (Lehmann et al., 2001) but the foundation can be laid at any stage depending on the awareness and life experiences of the individual.

\section{Character Strengths}

A "strength" is "a capacity for feeling, thinking, and behaving in a way that allows optimal functioning in the pursuit of valued outcomes" (Snyder \& Lopez, 2007).Character strengths are the psychological ingredients-processes or mechanisms - that define the virtues (Peterson \& Park, 2003). That is, character strengths are distinguishable routes to displaying one or another of the virtues. For example, the virtue of spirituality can be achieved through strengths such as humour, hope, gratitude and appreciation of beauty.

Six broad categories of character strengths emerged from Peterson and Seligman's work (2004), namely, Wisdom(creativity, curiosity, open-mindedness, love of learning and perspective), Courage (bravery, persistence, integrity and vitality), Humanity (love, kindness and social intelligence), Temperance (forgiveness, prudence, humility and self regulation), and Transcendence(appreciation of beauty, gratitude, hope, humor and spirituality).

\section{Coping Strategies}

Folkman and Lazarus (1985) defined coping strategies as constantly changing cognitive and behavioural efforts to manage the specific external or internal demands that are appraised as taxing or exceeding the resources of the person. Coping strategies are used to minimise stressful events and their corresponding effects. Tobin et al. (1989) gave two measures of coping such as Engagement and Disengagement coping strategies. Engagement coping strategy is characterised by active involvement in problem resolution through problem solving, cognitive restructuring, expressing emotions and social support. Disengagement coping strategy is characterised by disengaging from the stressful situations. On an average, it is considered to be an unhealthy way of dealing with problems. It involves the use of problem avoidance, wishful thinking, self criticism and social withdrawal coping strategies.

(C) The International Journal of Indian Psychology, ISSN 2348-5396 (e) | ISSN: 2349-3429 (p) | 216 


\section{Spiritual Intelligence in Relation to Character Strengths and Coping Strategies among Adolescents}

\section{Spiritual Intelligence and Coping strategies}

Spiritually intelligent cope with crisis by setting things in a sense of perspective, admitting mistakes and adversities, peacefully submitting themselves to the will of Higher God, finding a sense of purpose in crisis and by showing bravery to adjust and by being self reliant (Zohar \& Marshall, 2000).

Peaceful surrender to God requires one to be ego free, self aware, humble and calm (Hosseini et al., 2010). Dada et al. (2013) found that women who were spiritually intelligent used more of problem focused coping strategies as compared to women lower on spiritual intelligence. However, the results are contradictory as Sally (2006) found S.I to be strongly related to emotion focused coping strategy as compared to problem focused styles. Therefore, this finding supported the closer association between emotional intelligence and spiritual intelligence as a possibility.

\section{Spiritual Intelligence and Character Strengths}

As far as spirituality has been concerned, it is included as a virtue in the VIA list of character strengthsunder the category of Transcendence (Peterson \& Seligman, 2004). However, spiritual intelligence and its relations with character strengths have been unexplored. Based on the definitions and conceptualisation of spiritually intelligent people, the following strengths have been inferred:a) Love, forgiveness and critical thinking (as seen in the dimensions of critical existential thinking) (King \& Decicco, 2009). According to the religious philosophies, spiritually intelligent people are high on b) grace, forgiveness, gratitude and honesty; c) According to Wigglesworth (2002) commonly used descriptors for spiritual leaders are: loving, kind, forgiving, peaceful, courageous, honest, generous, persistent, faithful, wise and inspiring.

\section{Hypotheses:}

Based on the review of literature the following hypotheses were proposed:-

1) It is expected that Spiritual Intelligence and its dimensions viz., Critical Existential Thinking, Personal Meaning Production, Transcendental Awareness and Conscious State Expansion will be a) positively related to Engagement coping strategies and b) negatively related to disengagement coping strategies

2) It is expected that Spiritual Intelligence and its dimensions will be positively related to Character Strengths.

\section{METHOD}

\section{Sample}

Respondents comprised of 75 adolescents $(M$ age=17, S.D = 4.32) who were randomly selected from two government colleges of Chandigarh. The sample comprised of 40 females and 35 males who were students of humanities stream. There was a preponderance of participants belonging to middle socio economic status. 55\% of the sample was from Chandigarh, $25 \%$ of the sample from Panchkula and 20\% of the sample resided in Mohali. 52\% of the participants 


\section{Spiritual Intelligence in Relation to Character Strengths and Coping Strategies among Adolescents}

followed Hinduism, 26\% followed Sikhism, 10\% belonged to Islam and the remaining 12\% did not show any religious affiliation and chose spirituality as their only religious belief.

\section{Procedure}

A list of students was obtained from their respective colleges and classrooms. 80 students were randomly selected out of which 5 did not show any willingness to participate. Thus, 75 volunteers were finally chosen. They were ensured their confidentiality. Informed consent of the participants was taken. The administration of the tests took 1 hour. In exchange refreshments and small gifts were given.

\section{Measures}

Spiritual Intelligence-was measured using The Spiritual Intelligence Self-Report Inventory (King, 2008). SISRI-24 is a self report inventory consisting of 24 items that measure 4 Subscales/Factors namely: Critical Existential Thinking (CET; 7 items), Personal Meaning Production (PMP; 5 items), Transcendental Awareness (TA; 7 items), Conscious State Expansion (CSE; 5 items), and Total Spiritual Intelligence Score. The respondent had to circle the answer that seemed the best for that statement from $0=$ Not at all true to me to $4=$ completely true of me.

The Cronbach's alpha Reliabilities for the scales were- .88, .87, .89, .94 (CET, PMP, TA, and CSE, respectively). Average inter item correlations was .41, .47, .47, and .59.Construct validity, convergent validity, and divergent validity were well supported overall (King, 2008). SI was more significantly related to Intrinsic Religiosity (sincere adherence to the religious beliefs) than Extrinsic Religiosity (using religion for personal motive like socializing). No significant correlations were found between SI and IQ, ruling out IQ as a confounding variable.

Coping- was measured using 72-item self report Coping Strategies Inventory by Tobin et al. (1989). The format of the CSI is adapted from Lazarus "Ways of coping" questionnaire (Folkman \& Lazarus, 1984). Subjects were required to describe in a paragraph or two, the events of a stressful episode in Appendix A. After describing the event, they were required to respond to the items in Appendix B by choosing one option out of the 5 options available (none, a little, some, much and very much) keeping in mind the way they dealt with the event described in appendix A. Tertiary subscales of the inventory were used for the present study. These subscales gave a measure of engagement and disengagement coping strategies.

Engagement subscale included problem solving, cognitive restructuring, social support and expressing emotions strategies whereas disengagement subscale included problem avoidance, wishful thinking, social withdrawal and self criticism as its measures. All the 14 subscales were not selected in order to avoid the problem of collinearity between the scales. 


\section{Spiritual Intelligence in Relation to Character Strengths and Coping Strategies among Adolescents}

The alpha coefficients for CSI range from .71 to .94 (Tobin et al., 2001). In the manual alpha coefficients of .90 and .89 and test-retest reliabilities of .78 and .79 have been reported for engagement and disengagement scales, respectively. Further, the scale has highcriterion and construct validity.

Character strengths- were measured using Brief Strengths Test. This test was derived from a much longer 240-item VIA Signature Strengths inventory (Peterson \& Seligman, 2004). Scores from shorter test had been found to converge with scores derived from the longer test at approximately $r=.50$ (Price, 2007). Respondents were asked to think of actual situations in which they had shown that particular strength in the statement and choose one option from the 5 options (never/rarely, occasionally, half the time, usually, and always).

\section{Statistical Analysis}

Means and S.Ds for each variable were computed. Pearson's product moment correlation analysis was done for all the 31 variables. Multiple regression analysis was run to find out the significant contributors of spiritual intelligence, with S.I being the dependent variable and character strengths being the independent variable. Only those variables of character strengths were entered into the multiple regression equation which had significant correlations with S.I in the correlational analysis. The entire statistical analysis was computed through SPSS 16.0.

\section{RESULTS}

Descriptive statistics of Means and Standard Deviations have been shown in table 1. Correlation analysis and multiple regression results are shown in table 2 and 3.

\section{Bivariate correlation results:}

\section{Spiritual intelligence and coping strategies:}

Correlational analysis revealed a significant positive association between spiritual intelligence and engagement coping strategies $(\mathrm{p}<.01)$.Therefore, hypothesis 1.A has been accepted. Amongst the dimensions of spiritual intelligence, Critical existential thinking, Personal meaning production and Transcendental awareness showed a positive association with engagement coping strategy.Part B of hypothesis 1 did not come out to be significant as disengagement coping strategy did not show a negative association with S.I and its dimensions. Rather the correlation turned out to be close to zero ( $\mathrm{r}=0.05)$.

\section{Spiritual intelligence and character strengths:}

Hypothesis 2 has been accepted for 14 out of 24 character strengths. Spirituality, Gratitude, Self control, Love, Bravery $(\mathrm{p}<.01)$, Appreciation of beauty, Optimism, Leadership, Forgiveness, Social intelligence, Kindness, Love of learning, Curiosity, Critical thinking $(p<.05)$ emerged as significant positive correlates of Spiritual Intelligence. Only Humor $(p<.05)$ showed a negative relationship with S.I. 


\section{Spiritual Intelligence in Relation to Character Strengths and Coping Strategies among Adolescents}

\section{Multiple Linear Regression analysis}

Multiple linear regression analysis was used to develop a model for predicting Character Strengths from the subject's Spiritual Intelligence scores. Regression coefficients are shown in table 3 for model 1 (Strengths). Multiple regression model with all 14 predictors produced $\mathrm{R}=.48, \mathrm{R} 2=.23, \mathrm{~F}(14,61)=19.08, \mathrm{p}<.000$. The character strengths of spirituality, gratitude, self control, love, bravery, appreciation of beauty, optimism, leadership, forgiveness, social intelligence, kindness, love of learning, curiosity, critical thinking entered the final model at a significant level. Therefore 23\% of the variance in S.I is accounted by the above mentioned 14 character strengths.

\section{DISCUSSION}

From the results of engagement coping strategy and S.I. it is clear that spiritually intelligent adolescents actively participate in solving problems (emotional and problem focussed). In terms of the dimensions of S.I, it may be inferred that engagement coping style is related to finding a personal meaning of life, and being able to transcend one's personal boundaries, limitations and egos. Therefore, they are able to actively deal with stressors.

The result showing close to zero association of S.I. with disengagement coping strategy implies that it may not be necessary for spiritually intelligent adolescents to avoid disengaging coping strategies. It rather suggests that spiritual intelligence might also require one to take a distant view from the problem. This may happen in situations when one has to accept suffering and suffering is inevitable and unavoidable. In these moments of hardships spiritually intelligent people might show total disengagement and may either leave the solution into the hands of the divine energy or not get ego identified with the event. They are capable of accepting loss. According to Carver et al. (1989) disengagement or avoidant coping styles are not always undesirable. In some circumstances their usage is healthy and required. However, these findings may not be necessary across all the age groups and gender. Since, the present study studies only the late adolescent age group, further investigation of developmental differences in spiritual intelligence and corresponding coping mechanisms needs to be found out.

Considering the dimension of Critical existential thinking and its significant association with disengagement coping strategy, it can be inferred that critically contemplating the purpose and meaning of our existence might provide one with a lot of time to engage in contemplation, thus taking hands of dealing with the problem actively for a while. Positive association with Personal Meaning Production also suggests that without an active engagement one may not be able to achieve the personal meaning making aspect of spiritual intelligence.

In terms of character strengths it can be said that spiritually intelligent people possess various virtues which make them forgive others, love others, exhibit kindness and self control in everyday acts, appreciate the beauty of divine order, face obstacles persistently, be able to lead 


\section{Spiritual Intelligence in Relation to Character Strengths and Coping Strategies among Adolescents}

wisely, think critically, be able to remain optimistic about life, and have good understanding of other people through the virtue of social intelligence. Negative association of humor with S.I. has been a contradictory finding in the current study. Prior studies have revealed a positive association between humor and spirituality (Saraglou et al., 2008; Van Cappellen et al., 2013).

Therefore, the current study provides some insight into the profile of spiritually intelligent adolescents, and secondly, a suggestive step towards the inculcation of these virtues in order to facilitate overall spiritual development. The findings of this study can be used foster programmes on spiritual intelligence and its development by incorporating exercises for strength building and engagement coping mechanisms.

\section{LIMITATIONS AND FUTURE DIRECTIONS}

Firstly, keeping in view the differences in coping strategies used by different age groups, it would be required to study whether spiritually intelligent individuals of different age group would also show the same characteristics. This addition of another age group might throw some light on age group differences in spiritual intelligence. Secondly, based on the findings it is suggested to further understand in which situations spiritually intelligent individuals show disengagement coping strategy. Thirdly, instead of using the brief strengths survey, more accurate description of the association between character strengths and spiritual intelligence can be known by using the longer version of VIA character strength inventory. Fourthly, either spiritual intelligence requires certain virtues or it could also be a consequence of the above mentioned virtues and coping mechanisms. To obtain further clarity one needs to assess as to which variable is the cause and which one is the effect.

\section{Acknowledgments}

The author appreciates all those who participated in the study and helped to facilitate the research process.

\section{Conflict of Interests}

The author declared no conflict of interests.

\section{REFERENCES}

Benavides, L. E. (2010). Spirituality as protective factor for adolescents exposed to domestic violence. Unpublished doctoral dissertation. University of Texas, Arlington.

Bucke, M. A. (1969). Cosmic consciousness: A study in the evolution of the human mind. NewYork: E. P. Dutton.

Carver, C. S., Scheier, M. F., \& Weintraub, J. K. (1989). Assessing coping strategies: A theoretically based approach. Journal of Personality and Social Psychology, 56, 267-283.

Dada, F., Manshaee, G., \& Ebrahimi, A. (2013). Comparison of spiritual intelligence and strategy for coping with stress in women who are suffering from breast cancer and 


\section{Spiritual Intelligence in Relation to Character Strengths and Coping Strategies among Adolescents}

digestive system cancer in Esfahan city. Journal of Basic Applied Science Research, 3(8), 319-324.

Erikson, E. H. (1968). Identity: Youth and Crisis. New York: Norton.

Hosseini, M., Elias, H., Krauss, S. E., \& Aishah, S. (2010). A review study on spiritual intelligence, adolescence and spiritual intelligence: factors that may contribute to individual differences in spiritual intelligence, and related theories. International journal of Psychological Studies, 2(2), 179-188.

King, D. B. (2008). Rethinking claims of spiritual intelligence: A definition, model, and measure (Unpublished master's thesis). Trent University, Peterborough, Ontario,Canada.

King, D. B., \& DeCicco, T. L. (2009). A viable model and self-report measure of spiritual intelligence. International Journal of Transpersonal Studies, 28, 68-85.

Lazarus, R. S., \& Folkman, S. (1984). Stress, appraisal, and coping. New York: Springer.

Lehmann, D., Faber, P. L., Achermann, P., Jeanmonod, D., Gianotti, L. R., \& Pizzagalli, D. (2001). Brain sources of EEG gamma frequency during volitionally meditation-induced, altered states of consciousness, and experience of the self. Psychiatry Res. 108(2):111-21.

Maslow, A. H. (1964). Religions, Values and Peak-experiences. Columbus, Ohio: Ohio State University Press.

Parks, S. D. (2000). Big questions, worthy dreams: Mentoring young adults in their search for meaning, purpose, and faith. San Francisco: Jossey-Bass.

Peterson, C., \& Park, N. (2003). Positive psychology as the evenhanded positive psychologist views it. Psychological Inquiry, 14, 141-146.

Peterson, C.,\& Seligman, M. E. P. (2004). Character strengths and virtues: A handbook and classification. Washington, D.C.: American Psychological Association.

Price, A. O. (2007). Can Happiness be Taught? The effects on subjective well being of attending a course in positive psychology that includes the practice of multiple interventions. Unpublished doctoral dissertation, University of Canterbury, Christchurch, New Zealand.

Sally, I. M. (2006). The constructs of spiritual intelligence, its correlates with stress management and variation across selected variables. Unpublished doctoral dissertation, Saint Louis University, Baguio City.

Saroglou, V., Buxant, C., \& Tilquin, J. (2008). Positive emotions as leading to religion and spirituality. Journal of Positive Psychology, 3, 165-173.

Shivani, B. K. (2011, March 27). What is spiritual intelligence? TheTimes of India, pp, A.9.

Snyder, C. R., \& Lopez, S. J. (2007). Positive psychology: The scientific and practical explorations of human strengths. Thousand Oaks, CA: Sage.

Tobin, D. L., Holroyd, K. A., Reynolds, R. V., \& Wigal, J. K. (1989). 'The hierarchical factor structure of the Coping Strategies Inventory', Cognitive Therapy and Research, vol. 13(4), pp. 343-361.

VanCappellen, P., Saraglou, V., Iweins, C., Piovesana, M., \& Fredrickson, B. (2013). Self transcendent positive emotions increase spirituality through basic world assumptions. Coping and Emotion, 27, 1378-1394. 
Spiritual Intelligence in Relation to Character Strengths and Coping Strategies among Adolescents

Wigglesworth, C. (2002). Spiritual Intelligence and why it matters. Deep change, Distinctive Results.

Zohar, D., \& Marshall, I. (2000). Spiritual Intelligence, the ultimate intelligence. London: Bloomsbury

Table 1. Descriptive Statistics for Spiritual Intelligence, Character Strengths and Coping

Strategies $(n=75)$

\begin{tabular}{|c|c|c|}
\hline Variables & $\mathbf{M}$ & S.D \\
\hline \multicolumn{3}{|l|}{ Spiritual Intelligence dimensions } \\
\hline Critical Existential Thinking & 14.79 & 4.63 \\
\hline Personal Meaning Production & 12.63 & 3.33 \\
\hline Transcendental Awareness & 16.00 & 4.43 \\
\hline Conscious State Expansion & 10.60 & 4.06 \\
\hline Total Spiritual Intelligence & 54.15 & 12.59 \\
\hline \multicolumn{3}{|l|}{ Character Strengths } \\
\hline Appreciation of Beauty & 4.00 & 1.10 \\
\hline Optimism & 3.90 & 1.31 \\
\hline Humor & 3.90 & 0.91 \\
\hline Spirituality & 4.32 & 1.08 \\
\hline Gratitude & 4.32 & 1.08 \\
\hline Prudence & 2.79 & 1.37 \\
\hline Self control & 3.61 & 1.33 \\
\hline Leadership & 3.21 & 1.50 \\
\hline Modesty & 3.19 & 1.51 \\
\hline Fairness & 3.19 & 1.65 \\
\hline Forgiveness & 4.23 & 1.08 \\
\hline Love & 4.22 & 1.01 \\
\hline Social Intelligence & 3.54 & 1.39 \\
\hline Honesty & 3.43 & 1.38 \\
\hline Teamwork & 3.85 & 1.44 \\
\hline Kindness & 4.06 & 1.18 \\
\hline Zest & 3.64 & 1.28 \\
\hline Persistence & 2.91 & 1.42 \\
\hline Bravery & 3.90 & 1.26 \\
\hline Perspective & 3.90 & 1.36 \\
\hline Love of learning & 3.40 & 1.46 \\
\hline Creativity & 3.25 & 1.22 \\
\hline Curiosity & 3.50 & 1.45 \\
\hline Critical Thinking & 3.40 & 1.32 \\
\hline \multicolumn{3}{|l|}{ Coping Strategies } \\
\hline Engagement & 115.66 & 21.06 \\
\hline Disengagement & 102.72 & 18.83 \\
\hline
\end{tabular}

(c) The International Journal of Indian Psychology, ISSN 2348-5396 (e) | ISSN: 2349-3429 (p) | 223 
Spiritual Intelligence in Relation to Character Strengths and Coping Strategies among Adolescents

Table 2. Correlations between Spiritual Intelligence (its dimensions), Character Strengths and Coping Strategies ( $n=75)$

\begin{tabular}{|l|l|l|l|l|l|}
\hline VARIABLES & $\begin{array}{l}\text { TOTAL } \\
\text { S.I }\end{array}$ & CET & PMP & TA & CSE \\
\hline Engagement coping & $.32^{* *}$ & $.21^{*}$ & $.26^{* *}$ & $.23^{*}$ & .07 \\
\hline Disengagement coping & .05 & $.32^{* *}$ & -.15 & .00 & .03 \\
\hline Appreciation of Beauty & $.23^{*}$ & .16 & .08 & $.23^{*}$ & .06 \\
\hline Optimism & $.23^{*}$ & .04 & $.27^{* *}$ & $.24^{*}$ & .17 \\
\hline Humor & $-.20^{*}$ & $-.25^{*}$ & .08 & $-.20^{*}$ & $.23^{*}$ \\
\hline Spirituality & $.26^{* *}$ & .10 & $.25^{*}$ & $.36^{* *}$ & $.25^{*}$ \\
\hline Gratitude & $.31^{* *}$ & $.33^{* *}$ & $.23^{*}$ & $.43^{* *}$ & $.18^{*}$ \\
\hline Prudence & .14 & .11 & $.30^{* *}$ & .02 & $.24^{*}$ \\
\hline Self control & $.28^{* *}$ & .05 & .17 & $.22^{*}$ & $.37^{* *}$ \\
\hline Leadership & $.20^{*}$ & $-.20^{*}$ & .06 & .06 & .07 \\
\hline Modesty & .11 & .04 & .01 & $.23^{*}$ & .00 \\
\hline Fairness & .10 & .00 & .12 & .04 & $.24^{*}$ \\
\hline Forgiveness & $.24^{*}$ & $.33^{* *}$ & .00 & $.18^{*}$ & .00 \\
\hline Love & $.26^{* *}$ & $.23^{*}$ & .04 & .05 & $.34^{* *}$ \\
\hline Social Intelligence & $.20^{*}$ & .09 & .12 & $.21^{*}$ & $.20^{*}$ \\
\hline Honesty & .09 & .07 & .00 & .13 & $.21^{*}$ \\
\hline Teamwork & .03 & $-.20^{*}$ & .17 & .06 & .04 \\
\hline Kindness & $.20^{*}$ & $.26^{* *}$ & $.35^{* *}$ & .17 & .02 \\
\hline Zest & -.12 & $-.23^{*}$ & .08 & $.20^{*}$ & .03 \\
\hline Persistence & .05 & .09 & .05 & .17 & $-.22^{*}$ \\
\hline Bravery & $.38^{* *}$ & $.22^{*}$ & .12 & $.27^{*}$ & $.39^{* *}$ \\
\hline Perspective & .14 & .12 & .14 & .16 & .15 \\
\hline Love of learning & $.18^{*}$ & .07 & $.34^{* *}$ & .08 & $.23^{*}$ \\
\hline Creativity & .06 & .01 & .04 & .10 & -.12 \\
\hline Curiosity & $.19^{*}$ & .05 & $.39^{* *}$ & .15 & .13 \\
\hline Critical Thinking & $.18^{*}$ & .06 & $.19^{*}$ & .15 & .09 \\
\hline & 0.05 & $.18 * * a 5$ & 5 & \\
\hline
\end{tabular}

*pearson's correlation value significant at 0.05 level $=.18$, ${ }^{* *}$ pearson's correlation value significant at 0.01 level $=$ .26, $\mathrm{SI}=$ Spiritual Intelligence, $\mathrm{CET}=$ Critical existential thinking, $\mathrm{PMP}=$ Personal Meaning Production, $\mathrm{TA}=$ Transcendental awareness, CSE $=$ conscious state expansions

Table 3. Multiple Regression of Character Strengths on Spiritual Intelligence

\begin{tabular}{|l|l|}
\hline Multiple R & 0.48 \\
\hline R square & 0.23 \\
\hline Adjusted R square & 0.21 \\
\hline Standard error & 11.03 \\
\hline F & 19.08 \\
\hline Significance of F (p) & 0.000 \\
\hline
\end{tabular}

(c) The International Journal of Indian Psychology, ISSN 2348-5396 (e) | ISSN: 2349-3429 (p) | 224 
Spiritual Intelligence in Relation to Character Strengths and Coping Strategies among Adolescents

How to cite this article: M Sehgal, M Kanwar (2016), Spiritual Intelligence in Relation to Character Strengths and Coping Strategies among Adolescents, International Journal of Indian Psychology, Volume 3, Issue 4, No. 75, ISSN:2348-5396 (e), ISSN:2349-3429 (p), DIP:18.01.060/20160304, ISBN:978-1-365-50727-4 